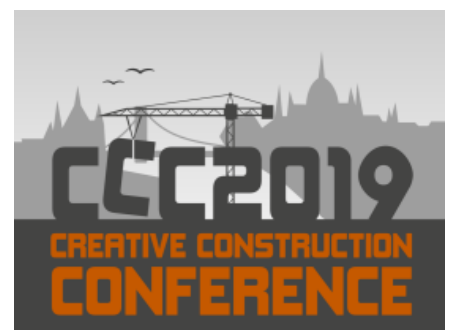

Available online at 2019.creative-construction-conference.com/proceedings/

CCC 2019

Proceedings of the Creative Construction Conference (2019) 118

Edited by: Miroslaw J. Skibniewski \& Miklos Hajdu

https://doi.org/10.3311/CCC2019-118

Creative Construction Conference 2019, CCC 2019, 29 June - 2 July 2019, Budapest, Hungary

\title{
Linking Revit Facility Life-Cycle Data to ARCHIBUS - A Case Study of an Academic Institution
}

\author{
Walid Thabet ${ }^{\mathrm{a}, *}$, Dan Miller ${ }^{\mathrm{b}}$ \\ ${ }^{a}$ Virginia Tech, Blacksburg, VA 24061, USA \\ ${ }^{b}$ Infrastructure Management Solutions, Vienna, VA 22182, USA
}

\begin{abstract}
Building owners and facility managers are beginning to leverage spatial information and asset data in BIMs for efficient and sustainable building operations and maintenance. Extracting information from BIMs for import into FM platforms still poses an implementation challenge to many owners. Methods for bi-directional synchronization of data between a BIM and FM software for real-time access to lifecycle model data can be more advantageous over one-way data export approaches so the owner can take advantage of an as-built BIM that can have data updated in real-time with continuous asset data updates. This paper uses a case study of a renovation project on a university campus to illustrate the use of the ARCHIBUS Smart Client for bidirectional real-time data exchange with Revit. The Archibus workflows were compared to other methods for data exchange as to how they support the needs of the owner. Lessons learned and challenges related to this workflow are discussed.
\end{abstract}

(C) 2019 The Authors. Published by Budapest University of Technology and Economics \& Diamond Congress Ltd.

Peer-review under responsibility of the scientific committee of the Creative Construction Conference 2019.

Keywords: Building Information Modeling; Facility Management; Revit; Archibus; Asset Properties; Life Cycle Data

\section{Introduction}

The number of building owners and facility managers needing to leverage spatial information and asset data in BIMs for efficient and sustainable building operations and maintenance continues to be on the rise. From a 2014 report, owners requested that BIM be used on $49 \%$ of the projects but only $25 \%$ of the owners in the survey required BIM to be used. In the same study, owners' involvement with BIM rose over a two-year period from $42 \%$ to $59 \%$ and was expected to continue to grow while expanding the level of involvement linked to BIM on the project [1]. Linking BIM data from the model to the FM system has proved very valuable as it reduces time and effort on the facility manager and allows for supporting immediate and efficient use of the CMMS prior to occupying the building [2]. This fosters more efficient work order management and building maintenance activities.

Extracting information from BIMs for import in FM platforms still poses an implementation challenge for many owners due to various barriers including lack of in-house technical skill, cost of system implementation, personnel or resource limitations, and lack of knowledge [3,4]. Proprietary BIM add-ins (or plug-ins) that provide direct synchronizing of BIMs with the FM software, including CMMS and IWMS systems, for real-time access to life-cycle model data provide an advantage over other solutions that use one-way data export approaches.

*Corresponding author: thabet@vt.edu 
Walid Thabet and Dan Miller / Proceedings of the Creative Construction Conference (2019) 118 https://doi.org/10.3311/CCC2019-118

This research resulted in the development of BIM-FM guidelines for a large educational university. Completed phases include data needs analysis and documenting the data into a Revit model. This paper examines one of the approaches explored to transfer the data from a Revit model into a CMMS for FM asset management.

\subsection{Information transfer}

Traditional workflows to get facility information into the owner's CMMS system use manual error prone processes that are time consuming and results in incorrect and incomplete information [5]. Using BIM as a data source to document facility information for post-construction use was proposed to streamline the workflow to get information into the CMMS in a more effective manner.

Prior research identified the information needs for the owner [6] and pilot tested electronic means for documenting the information through custom parameters within Revit [7]. In total, 80 assets are tracked by the owner with common parameters and customized attributes. Facility data is collected at various phases through construction to be supplied to the owner. Methods explored for data documentation included direct input into Revit schedule, the use of Navisworks DataTools, and third party plug-ins. Each method resulted in exporting schedule data from Revit into a CSV file, manipulating the file, and using Pentaho to map the data to appropriate fields with the CMMS.

The current phase of the research is exploring methods of reducing manual manipulation of the data. Three basic methods were explored as part of this research [8]. The first was to use Navisworks DataTools to document and track additional information and export data. The benefit of this method was an as-built model that can store structured and unstructured data through hyperlinks to related documents. The second method was to use Dynamo within Revit to create a customized workflow. Required information from the model was captured by the workflow and documented into an Excel spreadsheet in the required format that can be directly linked to the CMMS. In addition, the documentation of Dynamo to directly link the data to the SQL database and remove additional mapping needs was also explored. The last method was to explore the use of ARCHIBUS Smart Client and the corresponding Revit plugin to examine bi-directional data transfer between the Revit model and CMMS. The ARCHIBUS Smart Client workflow, challenges faced, and lessons learned are discussed in more detail in this paper.

\subsection{ARCHIBUS Smart Client and Extension for Revit}

ARCHIBUS is an enterprise asset management solution that provides asset lifecycle and maintenance management for all types of assets (including equipment and space) on a single platform. The ARCHIBUS Smart Client is a Windows application that is used for bulk data entry, data transfer, and importing and exporting data from other systems, such as Revit, into the ARCHIBUS platform. It also provides tasks for robust data analysis. The Smart Client presents data in grid views for easy access to bulk data. To exchange data with Revit, an ARCHIBUS plug-in known as ARCHIBUS Extension, provides the graphical interface between Revit and the ARCHIBUS Smart Client.

Using the ARCHIBUS Smart Client and the Extension, life-cycle parameter data captured in the Revit BIM model during the design and construction phases can flow in both directions and map directly into ARCHIBUS prior to or during commissioning and building handover.

One-way data export tools from Revit such as the COBie Data Export plugin, CTC Spreadsheet Link and Revit Reports Export process data in one direction out of Revit. With bidirectional data exchange capabilities, the ARCHIBUS Smart Client allows for automatic updating of the ARCHIBUS database. Similarly, information added or updated in ARCHIBUS platform is automatically transferred back to Revit to update the model parameters, allowing the BIM to remain up to date during the facility operation and maintenance phase.

These bidirectional workflows allow owners and facility managers to directly access and modify critical information from within Revit or ARCHIBUS, increasing flexibility and significantly reducing the level of effort required to update or edit data. Additionally, no intermediate steps are needed to transfer and link the exported data to the FM system as required by many one-way export tools. 
Walid Thabet and Dan Miller / Proceedings of the Creative Construction Conference (2019) 118 https://doi.org/10.3311/CCC2019-118

\section{Case study description}

To examine the ARCHIBUS Smart Client workflow a renovation case study project was used. The project consisted of a $\$ 1.7$ million (USD) HVAC, lighting, and exterior window upgrade of a 1953 Occupancy Class Group A laboratory and office building. As-built 2D drawings and project scope of work documents (submittals) were reviewed to understand the specifics of the renovation work. In total, 29 pieces of mechanical equipment in nine asset groups were included in the study. For the purpose of this paper, the asset group "Air Handler Unit" (AHU) is used as an example.

Since a Revit model was not available for this project, a basic model was created to resemble the main features of the architecture and all the mechanical components. The Revit model is shown in Figure 1. Data was identified by reviewing project documentation and then input into the model using the previously documented methods [7]. The air handler used as an example of the data flow for this paper was a make-up air handler with child assets of a supply fan, three heaters, and humidifier. The owner's data requirements used for tracking assets are divided into common asset properties and specific asset properties are listed in Tables 1 and 2 respectively. Each asset group has its own list of attributes. Common asset properties are further broken into five groups to match with the CMMS functionality that is currently in use. Common or specific asset properties that are associated with a particular piece of equipment are identified as "instance" (I) parameters within Revit and those that are dependent on the model type are identified as "type" (T) parameters.

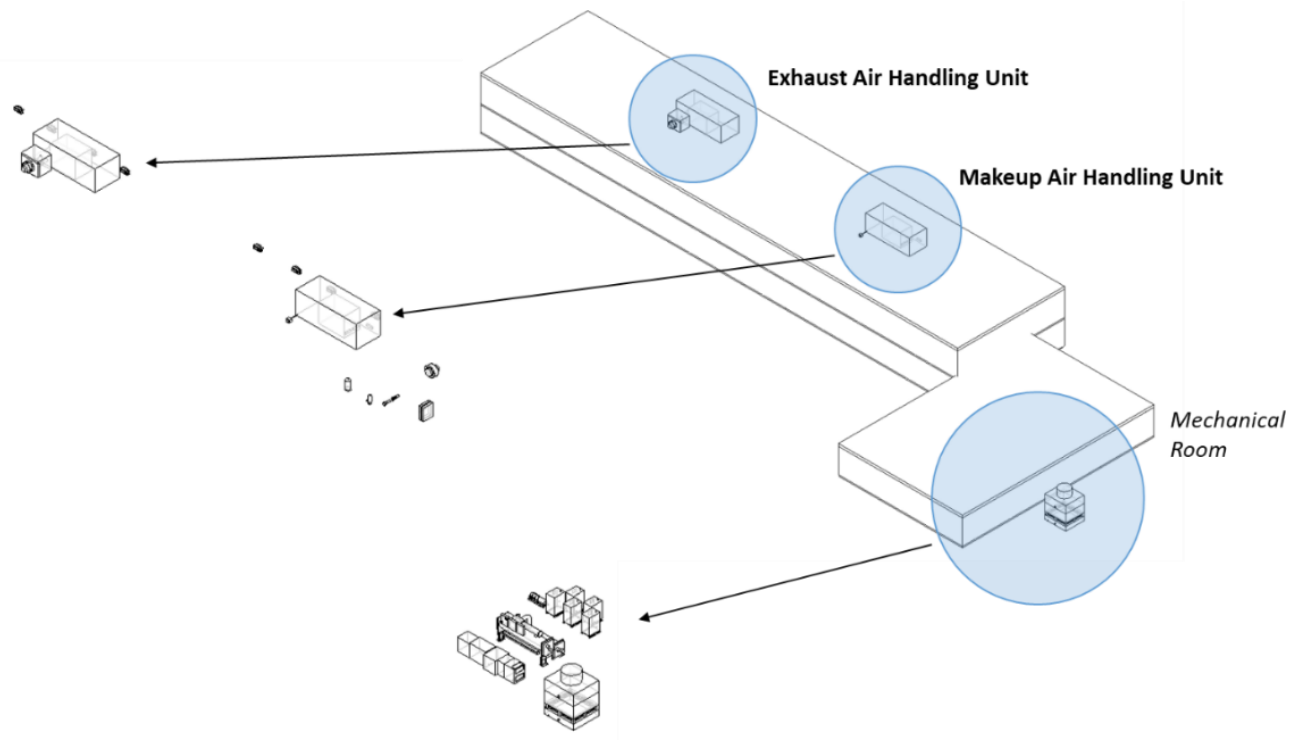

Fig. 1. Basic Revit model for the case study.

Table 1. Common Asset Properties.

\begin{tabular}{lllc}
\hline Category & Label & Description & Revit \\
\hline General & ASSET_TAG & Owner specified code & $\mathrm{I}$ \\
& ASSET_GROUP & AHU - Air Handler Unit & $\mathrm{T}$ \\
& DESCRIPTION & Example: MAKEUP AHU & $\mathrm{I}$ \\
& LOCATION_CODE & Example: ROOF & $\mathrm{I}$ \\
DATE_PURCHASED & Purchase date & $\mathrm{I}$ \\
& LONG_DESC & Long description of asset & $\mathrm{T}$ \\
LOCKOUT & Yes or no - lockout required & $\mathrm{T}$ \\
SERIAL_NO & Serial Number & $\mathrm{I}$ \\
MANUFACTURE_CODE & Manufacture (TRANE) & $\mathrm{T}$ \\
& MANU_PART_NUMBER & Part number by manufacture & $\mathrm{T}$ \\
& PROCEDURE_YN & Specific run procedure & $\mathrm{T}$ \\
& PARENT_ASSET_TAG & If the asset has a parent & $\mathrm{I}$ \\
& YEAR_INSTALLED & & $\mathrm{I}$
\end{tabular}


Walid Thabet and Dan Miller / Proceedings of the Creative Construction Conference (2019) 118 https://doi.org/10.3311/CCC2019-118

\begin{tabular}{lllr}
\multirow{2}{*}{ Parts } & PART & Common maintenance parts & T \\
\multirow{4}{*}{ Warranty } & QUANTITY & Quantity needed & T \\
& WARR_DESC & Warranty Included & T \\
& WARR_DATE_FR & Warranty coverage start & I \\
\multirow{2}{*}{ Locations Served } & WARR_DATE_TO & Warranty coverage end & $\mathrm{I}$ \\
Classification & USATION & Location equipment serves & $\mathrm{I}$ \\
& CLASS_STANDARD & \% of each location served & $\mathrm{I}$ \\
\hline
\end{tabular}

Table 2. Specific Asset Properties - Air Handler Unit.

\begin{tabular}{llc}
\hline Asset Attribute Label & Description & Revit \\
\hline BAS POINT ADDRESS & ID in Bldg. Auto. System & $\mathrm{I}$ \\
HEATING SOURCE & Example: BOILER & $\mathrm{T}$ \\
HEATING CAPACITY & Volume of air & $\mathrm{T}$ \\
TOTAL AIR FLOW & Volume of air & $\mathrm{T}$ \\
EXTERNAL STATIC PRESSURE & & $\mathrm{T}$ \\
MIN. OUTSIDE AIR & & $\mathrm{T}$ \\
MAX. OUTSIDE AIR & Example: Chiller & $\mathrm{T}$ \\
COOLING SOURCE & & $\mathrm{T}$ \\
TOTAL COOLING CAPACITY & & $\mathrm{T}$ \\
SENSIBLE COOLING CAP & Yes or No (is there one) & $\mathrm{T}$ \\
ECONOMIZER & & $\mathrm{T}$ \\
ECONOMIZER TYPE & & $\mathrm{T}$ \\
TOTAL STATIC PRESSURE & Example: Roof Top & $\mathrm{T}$ \\
TYPE & & $\mathrm{T}$ \\
\hline
\end{tabular}

\section{Data transfer using ARCHIBUS plugin and Smart Client}

The overall process with a de-tailed description of the data exchange process of linking Revit to ARCHIBUS database using ARCHIBUS Extension and Smart Client Ver. 23 is summarized in Figure 2.

\section{Results}

This paper provided an overview for the ARCHIBUS Smart Client and Extension Ver. 23. ARCHIBUS Smart Client and Extension for Revit connect parameter information defined in Autodesk Revit with the ARCHIBUS asset management and maintenance platform. The Smart Client synchronizes data in both directions enabling owners and facility managers to modify equipment and space maintenance information in either platform, significantly improving data editing and updating workflows and reducing the level of effort required to access the information.

Several issues and lessons learned related to the ARCHIBUS Extension were observed and documented.

1. Revit Assemblies are not recognized - Elements with parent-child relationships (e.g. air handling units with fans installed in the overall assembly) were first modeled as Revit Assemblies by combining various mechanical components. This allowed the assemblies (AHU) and the components within the assembly (FAN) to have their own independent parameters. However, the ARCHIBUS Extension does not recognize assemblies as graphical elements to be mapped through the Smart Client to the ARCHIBUS platform. In addition, Revit does not allow for defining customizable parameters for different types of assemblies so they could not adequately represent the parent-child relationship required for the facility management platform. An alternative solution, though not graphically the best option, families were modeled in the same geometric space to represent both the parent and child assets. For instance, a non-descript block is used to identify the location and size of the air handling unit (AHU). This modeled object can then support the attributes and parameters associated with the AHU asset type.

2. The 'Default' dropdown is not labeled and must be changed to 'Equipment' before logging anything (Figure 3) This process could use more clarity on what the dropdown list is, as well as how critical it is to select Equipment when cataloguing data. Possibly place this dropdown menu in a more strategic location within the plugin. 
Walid Thabet and Dan Miller / Proceedings of the Creative Construction Conference (2019) 118 https://doi.org/10.3311/CCC2019-118

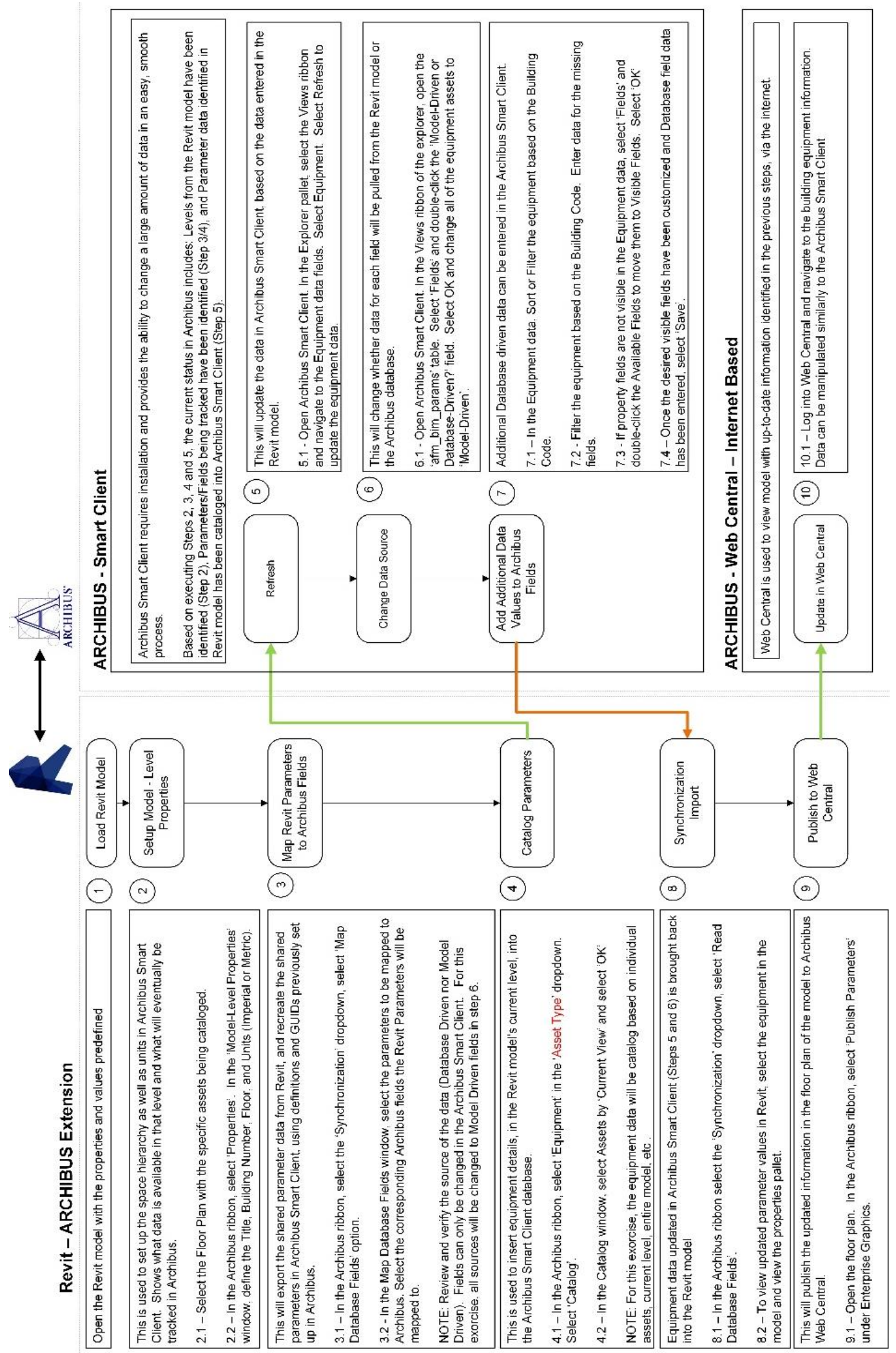

Fig. 2. Revit - ARCHIBUS data exchange process. 


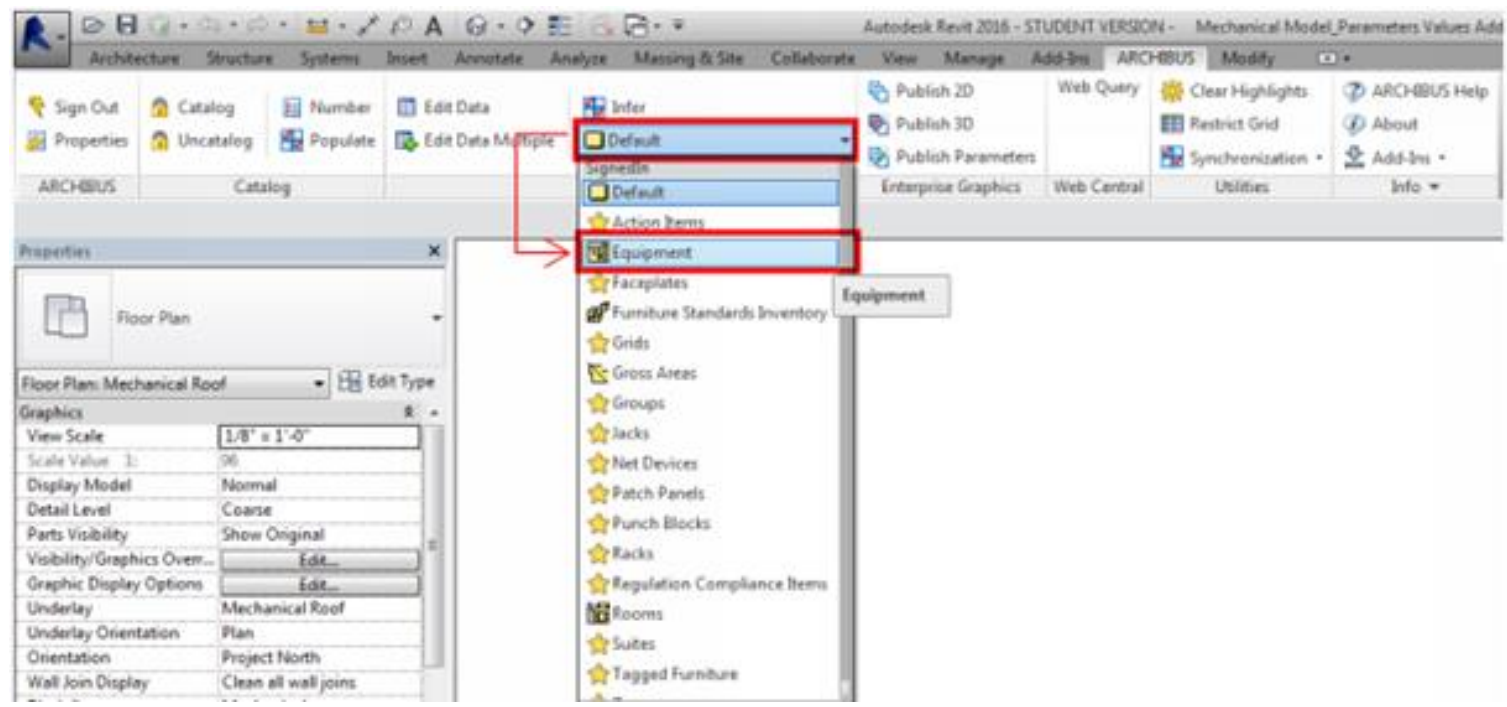

Fig. 3. Selecting Equipment in the Default Menu.

3. Cannot change the data source (Model Driven vs. Database Driven) in Revit - User must return to the Smart Client to change the data source. The Data Source allows to define the default source for the life cycle data for any asset; the Revit model or the ARCHIBUS Smart Client. The user can then map parameter fields and catalog data without having to return to the Smart Client.

4. Cannot add a new field or change an existing ARCHIBUS field - Revit parameters are mapped to ARCHIBUS fields that reside in its database. Adding new fields or editing existing fields can only be done in the Smart Client. Also adding new fields is a tedious and confusing process. To allow a user friendly process, fields should be modified within the ARCHIBUS Extension and the process should be streamlined.

5. When a change is made in the ARCHIBUS database using the Smart Client, the changes are not automatically reflected in the Revit model. Also there is no refresh button available in Revit to update the data. It is very cumbersome to go search for map database fields each time a change is made in database driven fields.

6. Naming convention for ARCHIBUS fields should be better explained - Identifying the appropriate ARCHIBUS field to map the Revit parameter to is cumbersome and unclear. It would be helpful to easily provide a formal list of current default ARCHIBUS fields with description to simplify the mapping process.

7. When creating/manipulating tables, the add fields option doesn't always display the same/all of the available fields in Smart Client. System should allow user to have access to all fields when adding fields to tables. For example: In equipment table in Smart Client, the 'Field Name' is displayed, but this is only abbreviations for the equipment fields. Example: num_serial is displayed instead of Serial Number. Add the field that would display the actual field and not the abbreviation to the available fields in the Add Field window.

\section{Conclusion}

The purpose of the project was to identify how a proprietary workflow of the ARCHIBUS Smart Client can be used to support data transfer needs on a pilot project into the Archibus CMMS. The pilot project involved mechanical and electrical assets that were being tracked as part of a lab building update on campus. When this 
was complete, lessons learned were identified on the project. A comparative analysis was also completed as to how this process related to other processes that were explored.

Overall, there are benefits to a clear bidirectional workflow that Archibus provides with a Revit plug-in that allows users to easily map Revit parameters to Archibus fields. It is easy to change and update the data extraction needed and format required. Though data export tools such as Dynamo proved to be very customizable for a system that does not have a plug-in for direct data export through Revit, it does require extensive programming when modifying the data output needs.

For the case study project looked at, the owner would be required to adopt a completely new CMMS system in order to take advantage of the Archibus plug-in which was the motivation for examining the workflows. The ultimate decision was to keep their current CMMS platform and develop a customized workflow to extract model data and import into the CMMS while working with their current platform vendor to develop a more user friendly plug-in that will not require modifying their current data and workflows to a new CMMS system.

\section{References}

[1] Bernstein, H. The Business Value of BIM for Owners, SmartMarket Report, McGraw Hill Construction Research \& Analytics, MA (2014).

[2] Teicholz, P. BIM for Facility Managers, John Wiley \& Sons, New Jersey, US (2013).

[3] Mayo, G., Giel, B., Issa, R.R.A. BIM Use and Requirements among Building Owners. Proc, Int. Conf. on Computing in Civil Engineering, ASCE, Clearwater, FL, 349-356 (2012). https://doi.org/10.1061/9780784413982.ch10

[4] Bercerik-Gerber, B., Jazizadeh, F., Li, N., Calis, G. Application Areas of Data Requirements for BIM-Enabled Facility Management, J. of Construction Engineering and Management, 138(3), 431-442 (2012). https://doi.org/10.1061/(ASCE)CO.1943-7862.0000433

[5] Thabet, W., Lucas, J., Johnston, S. A Case Study for Improving BIM-FM Handover for a Large Educational Institution. Construction Research Congress 2016, ASCE, Reston VA, 2177-2186 (2016). DOI/10.1061/9780784479827.217

[6] Thabet, W., Lucas, J. Asset Data Handover for a Large Educational Institution: Case-Study Approach, Journal of Construction Engineering and Management, 143(11), 05017017 (2017). DOI/10.1061/(ASCE)CO.1943-7862.0001389

[7] Thabet, W., Lucas, J. A 6-Step Systematic Process for Model-Based Facility Data Delivery. Journal of Information Technology in Construction (ITCon), Vol. 22, 104-131 (2017), http://www.itcon.org/2017/6.

[8] Lucas, J., Thabet, W. Using a Case-Study Approach to Explore Methods for Transferring BIM-Based Asset Data to Facility Management Systems. Construction Research Congress 2018, ASCE, Reston VA, 439-448 (2018). DOI/10.1061/9780784481264.043 